\title{
Impact of nursing interventions and patients education on quality of life regarding renal stones treated by percutaneous nephrolithotomy
}

\author{
Rasha Ali Ahmed Abdelmowla *1, Attyiat Hassan Hussein ${ }^{1}$, Ahmed Abdelhamaid Shahat ${ }^{2}$, Hanan Ali Ahmed \\ Abdelmowla ${ }^{1}$, Medhat Ahmed Abdalla ${ }^{2}$ \\ ${ }^{1}$ Department of Adult Nursing (Medical Surgical), Faculty of Nursing, Assiut University, Egypt \\ ${ }^{2}$ Department of Urology, Faculty of Medicine, Assiut University, Egypt
}

Received: April 28, 2017

DOI: $10.5430 /$ jnep.v7n12p52

\author{
Accepted: July 9, 2017 \\ Online Published: July 19, 2017 \\ URL: https://doi.org/10.5430/jnep.v7n12p52
}

\begin{abstract}
Background and objective: Renal stones are a common and recurrent condition that requires medical or surgical treatment; all have significant impact on quality of life. The objective of this study was to detect factors affecting quality of life, improve quality of life for patients with renal stones treated by percutaneous nephrolithotomy.

Methods: Research design: Prospective randomized controlled trail. Patients and methods: Random sample of 160 patients with renal stones planned for treatment by percutaneous nephrolithotomy at Assiut Urology and Nephrology Hospital were randomized into study and control groups. Study group (80 patients who received nursing interventions and patients education) and control group (80 patients who received routine hospital care). Their age ranged from18-65 years from both sexes. Tools: I Patient assessment sheet, II Rand short form 36 items questionnaire and III Teaching booklet.

Results: Study group was showed a good improvement on quality of life after providing nursing interventions and patients education.

Conclusions and recommendation: Nursing interventions and patients education for study group had a favorable effect on improving quality of life. Patients with percutaneous nephrolithotomy should receive careful care and education to improve their quality of life.
\end{abstract}

Key Words: Quality of life, Renal stones, Percutaneous nephrolithotomy

\section{INTRODUCTION}

Urinary stones are the third common problem in urology hospitals after urinary tract infections and prostate disease ${ }^{[1]}$ with a prevalence of more than $10 \%$ and a recurrence rate about $50 \%$, urinary stones has important effects in health care system and patients' quality of life. ${ }^{[2]}$

The main goal of surgical management for renal stones is complete stone free. ${ }^{[3]}$ In the last few decades, percutaneous nephrolithotomy has replaced open renal surgery and became the first line for management of complex or large renal stones. The main advantage of percutaneous nephrolithotomy is the ability to completely and rapidly clear a large stone without the attendant risks associated with fragment passage. ${ }^{[4]}$

Quality of life has been recognized as an important outcome measure following treatment of urological disease. It measures the difference between the person's hopes and expectation against their present condition in respect of current experiences. ${ }^{[5]}$ Percutaneous nephrolithotomy is expected

*Correspondence: Rasha Ali Ahmed Abdelmowla; Email: rashaali249@yahoo.com; Address: Faculty of Nursing, Assiut University, Egypt. 
to improve quality of life for patients with renal stones by alleviating the symptoms and preventing renal damage. However, percutaneous nephrolithotomy as a minimally invasive procedure can result in complications such as bleeding in or around the kidney, infection, bowel perforation or renal dysfunction, which may affect quality of life in a negative manner. ${ }^{[6]}$

All patients undergoing percutaneous nephrolithotomy need preoperative and postoperative care by the nurse. Close observation and standard care for improving the success rate of interventions and prevention of complications is important. ${ }^{[7]}$ The nurse must have thorough understanding of patients' needs to provide optimal nursing interventions and patient education and thus improve their health. Nurse should emphasize to the patient the importance of reporting symptoms to physician immediately. Postoperative care should include: close monitoring of vital signs, close observation of urine output and color changes, wound care and careful observation for dressing and tube drainage, prevention of infection and prevention and monitoring for postoperative complications. Nurse should assess indwelling catheter and perform catheter care to early detect and prevent urinary tract infection. ${ }^{[8]}$

Patients' education is defined as any set of planned educational activities developed to improve health behaviors, health status, quality of life, or slow deterioration. Informed and educated patients can actively participate in their own treatment, improve outcomes, help in identifying errors before they occur, and reduce their length of hospital stay. Medical components of health education involves medical information and preventative measures concerning health and well-being. ${ }^{[9]}$ Patients' education should concerned with diet, activity, medications, bowel, dressing, nephrostomy tube care for percutaneous nephrolithotomy, expected symptoms and follow up appointments. ${ }^{[10]}$

\subsection{Aims of the study}

\subsubsection{General objective}

Evaluate the impact of nursing interventions and patients education on quality of life for patients with renal stones treated by percutaneous nephrolithotomy.

\subsubsection{Specific objectives}

(1) Detect factors affecting quality of life for patients with renal stones.

(2) Improve quality of life for patients with renal stones treated by percutaneous nephrolithotomy.

\subsection{Research hypothesis}

Nursing interventions and patients education will improve quality of life for patients with renal stones treated by percu-

Published by Sciedu Press taneous nephrolithotomy.

\section{Patients and methods}

\subsection{Research design}

Prospective randomized controlled trial.

\subsection{Setting}

The study was conducted at Assiut Urology and Nephrology Hospital, Egypt.

\subsection{Patients}

Random sample of 160 adult patients with renal stones planned for treatment by percutaneous nephrolithotomy. Their age ranged from 18 to 65 years from both sexes. There are two groups of patients: study group ( 80 patients received nursing interventions and education) and control group (80 patients received routine hospital care). Closed envelope method was used to distribute the patients on two groups randomly. Data collected within one year (from December 2015 to December 2016); this period included time of assessment, providing nursing interventions, patients education and follow up. Patients' assessment was performed immediately after admission to Assiut Urology and Nephrology Hospital and daily till discharge. During preoperative and postoperative periods the main researcher provides nursing interventions, educate patients and introduce the teaching booklet. Patients were followed up after 3 and 6 months at Assiut Urology and Nephrology outpatient clinic.

\subsection{Exclusion criteria}

Bleeding tendencies, recurrent stones, bilateral stones, active urinary tract infection, pregnancy, distal ureteral obstruction, marked obesity (BMI $>40$ ) or patients did not complete follow up period.

\subsection{Tools}

\subsubsection{Tool I: Patients assessment sheet}

It was developed by researchers after review of national and international literatures to assess demographic data, health history, medical data, operative and postoperative data, physical status and factors affecting quality of life. This tool consisted of five parts:

Part I: Demographic data: Name, age, gender, level of education and occupation.

Part II: Health history:

(1) Medical data: Diagnosis, clinical manifestations, vital signs and criteria of disease.

(2) Preoperative factors that may affect quality of life: Chronic diseases, presence of stent, laboratory investigations and diagnostic procedures. 
(3) World Health Organization Performance Status Scale: Designed by Oken et al. (1982). ${ }^{[11]}$ It is used to assess how disease affects daily living abilities of patient and describes the status of symptoms and functions. It consists of:

- Grade 0: Normal activity.

- Grade 1: Restricted in physical strenuous activities but ambulatory and able to carry out work of light or sedentary nature.

- Grade 2: Less than $50 \%$ of daytime in bed.

- Grade 3: More than 50\% of daytime in bed.

- Grade 4: Completely disabled.

- Grade 5: Dead.

Part III: Operative and post-operative data: It includes method of stone treatment (percutaneous nephrolithotomy), length of hospital stay, renal function test, and auxiliary maneuvers. It includes postoperative factors affecting quality of life: postoperative double $\mathbf{J}$ stent, performance status, stone clearance and complications.

Part IV: Clavien-Dindo grading system for the classification of surgical complications: Developed in 1992 by Clavien et al., was reevaluated and modified in 2004 by Dindo et al. ${ }^{[12]}$ It is used to classify complications based on life-threatening conditions, interventions required and disability.

Part V: Patients' knowledge regarding percutaneous nephrolithotomy: It was developed by researchers after national and international review of literatures, including 20 questions concerning definition of percutaneous nephrolithotomy, indications, contraindications, medical treatment, preoperative care, postoperative care, postoperative complications, follow up, home care and discharge instructions (diet, activity, medications, dressing, expected and warning symptoms).

Scoring system: Each right answer was given one score. The total score was 20 degree. Those who obtained less than $75 \%$ were considered having unsatisfactory level. $75 \%$ and above were considered having satisfactory level.

\subsubsection{Tool II: Rand short form 36 items questionnaire}

It contains 36 questions and measures quality of life. It divided into eight scales plus one health comparison question (health change). Scoring system for Rand short form 36 questionnaire: ${ }^{[13]}$ Each scale contains from 2-10 items. All questions are scored on a scale from 0 to 100 , high scores is an indicative of improved outcome.

\subsubsection{Tool III: Teaching booklet for patients with renal stones treated by percutaneous nephrolithotomy}

Designed by researchers according to patients' needs after reviewing national and international literatures to improve quality of life for patients after percutaneous nephrolithotomy. It includes:

- Function of the kidney.

- Definition of percutaneous nephrolithotomy.

- Indications and contraindications of percutaneous nephrolithotomy.

- Preoperative care for percutaneous nephrolithotomy.

- Postoperative care after percutaneous nephrolithotomy.

- Postoperative complications after percutaneous nephrolithotomy.

- Home care and discharge instructions after percutaneous nephrolithotomy:

- Medication.

- Deep breathing and coughing exercises.

- Diet.

- Intake and output of liquids.

- Activity.

- Expected and warning symptoms.

- Showering.

- Nephrostomy tube care/dressing.

- Follow up appointments.

\subsection{Methods}

Official permission was obtained from the head of urology department and local ethical committee. The researchers designed and tested the study tools and the teaching booklet after reviewing extensive literatures. Informed consent was obtained from patients in this study after explanation to the nature and purposes of study.

Content validity was done by 5 expertise: 2 expertise from medical-surgical nursing staff and 3 from urology staff who reviewed the tools and the teaching booklet for clarity, relevance, comprehensiveness, understanding, applicability and easiness for administration. The content is valid and reliable. Reliability was assessed by correlation coefficient with $>0.8$ considered strong.

Pilot study was conducted on $10 \%$ of patients ( 8 patients from each group) in Assiut Urology and Nephrology Hospital for testing applicability, clarity and feasibility of study tools. No changes were done for study tools, so the $10 \%$ of patients were included in the study.

At the first interview the main researcher introduce self, explain nature and purposes of the study. Patients with renal stones treated by percutaneous nephrolithotomy were visited daily during preoperative and postoperative periods till discharge to assess patients' knowledge and conditions. Control group received routine hospital care while study group 
received routine hospital care in addition to nursing interventions and patients education (teaching booklet) provided by the main researcher. Nursing interventions aimed to relieving pain, prevent infection, monitoring and managing potential complications and promoting home and community based care. During preoperative period the main researcher assess factors affecting preoperative quality of life, perform physical examination for patients, assess for any allergies, report any medications taken to the surgeon, insure that patients were fit for surgery and the following preoperative testing done prior to surgery: electrocardiogram, complete blood count, blood coagulation profile, blood chemistry profile and urinalysis.

During postoperative period the main researcher asked patients who remain in bed at first to move feet and ankles, and wiggle toes to help encourage circulation in legs to reduce the risk of blood clots in legs, encourage patients to perform deep breathing and coughing exercises, monitor vital signs, monitor intake and output, close observation of urine color changes, nephrostomy tube care/dressing, careful observation for wound (observe discharge for color, amount, odor and consistency), observe and care of postoperative bleeding, observe for signs and symptoms of infection, proper positioning of patients, assess indwelling urinary catheter, perform catheter care, empty the bag and measure the volume of urine produced, guide patients after surgery to increase water intake (8 to 10 cups), increased urination and not holding back urine. With tubes not perform strenuous activities during the period, careful monitoring and management of postoperative complications, assess factors affecting postoperative quality of life, and report any abnormality to the surgeon.

Quality of life during preoperative period was assessed using Rand short form 36 items questionnaire. Teaching booklet was introduced to patients in study group through individualized sessions. Three educational sessions were conducted for patients. Duration of each session was 40-45 minutes, in addition to 15-30 minutes to discuss any questions and regain feedback. Patients were educated briefly about function of kidney, definition, indications, contraindications, preoperative and postoperative care for percutaneous nephrolithotomy and postoperative complications after percutaneous nephrolithotomy. Home care and discharge instructions after percutaneous nephrolithotomy were explained in details to the patients concerning medication, deep breathing and coughing exercises, diet, intake and output of liquids, activity, expected and warning symptoms, showering, nephrostomy tube care/dressing and follow up appointments.

Complications were assessed immediately after percutaneous nephrolithotomy and through period of 6 weeks using

Published by Sciedu Press
Clavien-Dindo grading system for the classification of surgical complications (tool I, part IV). Follow up was done for both groups of patients for 3 and 6 months after surgical management in outpatient clinic of Assiut urology and nephrology hospital. Some patients followed up by phone and report some postoperative complications. The main researcher asked them to attend to outpatient clinic of Assiut urology and nephrology hospital. Those patients were attended to outpatient clinic of Assiut urology and nephrology hospital and the health care team treat them promptly and thus led to early detection of complications, improve prognosis and prevent further complications. Abdominal ultrasound or $\mathrm{x}$-ray was performed to all patients in both groups immediately postoperative, after 3 and 6 months to evaluate stone free. Patients' knowledge was reassessed for both groups using (part V, tool I) after 3 and 6 months. Also, at the end of follow up period (after 6 months), quality of life was reassessed for both groups of patients using (tool II).

\subsection{Statistical analysis}

Statistical analysis for the collected data was done using IBM SPSS 19. Student $t$-test was used to analyze quantitative data, while Pearson chi square test and Fisher-exact test were used to analyze qualitative data. $P$ value $<.05$ was interpreted as a level of statistical significance for testing research hypothesis.

\section{Results}

Table 1 showed that more than half of patients in both study and control groups were males. The mean age were $38.52 \pm$ $15.84,40.32 \pm 12.87$ respectively. The majority of patients in both groups were educated and employed.

Table 2 illustrated non statistical significant differences between the two groups as regarding preoperative factors affecting quality of life (GFR, chronic diseases, preoperative double $\mathbf{J}$ stent, preoperative percutaneous nephrostomy and preoperative performance status).

Table 3 showed there were non statistical significant differences on quality of life for patients in both groups as regarding the 8 domains of the short form 36 items questionnaire (physical function, physical role limitation, emotional role limitation, vitality, mental health, social function, pain and general health).

Table 4 showed that there were significant relations between preoperative physical function, physical role limitation, emotional role limitation, vitality, mental health, social function, general health and pain as regarding preoperative double $\mathrm{J}$ stent for all groups of patients. There were none statistical significant relations between preoperative physical function, 
physical role limitation, emotional role limitation, vitality, Figure 1 illustrated that there was significant relation between mental health, social function, general health and pain as preoperative performance status and preoperative quality of regarding preoperative percutaneous nephrostomy, GFR and life for all groups of patients.

chronic diseases for all groups of patients.

Table 1. Demographic characteristics of patients with renal stones treated by percutaneous nephrolithotomy

\begin{tabular}{|c|c|c|c|c|}
\hline \multirow{2}{*}{ Demographic characteristics } & \multicolumn{2}{|c|}{ Study group $($ No. $=80)$} & \multicolumn{2}{|c|}{ Control group $($ No. $=80)$} \\
\hline & No. & $\%$ & No. & $\%$ \\
\hline Age (years) Mean \pm SD & $38.52 \pm 15.84$ & & $40.32 \pm 12.87$ & \\
\hline \multicolumn{5}{|l|}{ Sex } \\
\hline Male & 56 & 70 & 52 & 65 \\
\hline Female & 24 & 30 & 28 & 35 \\
\hline \multicolumn{5}{|l|}{ Level of education } \\
\hline High & 24 & 30 & 17 & 21.25 \\
\hline Moderate & 30 & 37.5 & 35 & 43.75 \\
\hline Low & 18 & 22.5 & 14 & 17.5 \\
\hline Read and write & 4 & 5 & 6 & 7.5 \\
\hline Illiterate & 4 & 5 & 8 & 10 \\
\hline \multicolumn{5}{|l|}{ Occupation } \\
\hline Mental & 18 & 22.5 & 16 & 20 \\
\hline Manual & 46 & 57.5 & 48 & 60 \\
\hline None & 16 & 20 & 16 & 20 \\
\hline
\end{tabular}

Table 2. Preoperative factors affecting quality of life in patients with renal stones planned for treatment by percutaneous nephrolithotomy

\begin{tabular}{|c|c|c|c|c|c|}
\hline \multirow{2}{*}{ Preoperative factors affecting quality of life } & \multicolumn{2}{|c|}{ Study group $($ No. $=80)$} & \multicolumn{2}{|c|}{ Control group (No. = 80) } & \multirow{2}{*}{$P$-value } \\
\hline & No. & $\%$ & No. & $\%$ & \\
\hline \multicolumn{6}{|l|}{ Glomerular filtration rate (GFR) } \\
\hline$>60 \mathrm{ml} / \mathrm{min} / 1.73 \mathrm{~m}^{2}$ & 29 & 36.2 & 25 & 31.25 & \multirow[t]{2}{*}{.348} \\
\hline$<60 \mathrm{ml} / \mathrm{min} / 1.73 \mathrm{~m}^{2}$ & 22 & 27.5 & 15 & 18.75 & \\
\hline \multicolumn{6}{|l|}{ Chronic diseases } \\
\hline Ischemic heart disease & 1 & 1.25 & - & - & \multirow{3}{*}{.426} \\
\hline Diabetes mellitus & 10 & 12.5 & 10 & 12.5 & \\
\hline Hypertension & 9 & 11.25 & 13 & 16.25 & \\
\hline Preoperative double $\mathrm{J}$ stent & 24 & 30 & 16 & 20 & .542 \\
\hline Preoperative percutaneous nephrostomy & 3 & 3.75 & 3 & 3.75 & .534 \\
\hline \multicolumn{6}{|l|}{ Preoperative performance status } \\
\hline I & 25 & 31.25 & 23 & 28.75 & \multirow{4}{*}{.143} \\
\hline II & 50 & 62.5 & 55 & 68.75 & \\
\hline III & 3 & 3.75 & 1 & 1.25 & \\
\hline IV & 2 & 2.5 & 1 & 1.25 & \\
\hline
\end{tabular}

Table 3. Preoperative quality of life using 8 domains of the short form 36 items questionnaire in patients with renal stones planned for treatment by percutaneous nephrolithotomy

\begin{tabular}{|c|c|c|c|}
\hline \multirow{2}{*}{ Preoperative quality of life domains } & Study group $($ No. $=\mathbf{8 0})$ & Control group (No. = 80) & \multirow{2}{*}{$P$-value } \\
\hline & $\overline{\mathbf{X}} \pm \mathbf{S D}$ & $\overline{\mathbf{X}} \pm$ SD & \\
\hline Physical function & $34.71 \pm 10.96$ & $32.07 \pm 12.39$ & .123 \\
\hline Physical role limitation & $29.39 \pm 8.62$ & $31.40 \pm 11.27$ & .128 \\
\hline Emotional role limitation & $37.07 \pm 9.54$ & $36.62 \pm 10.37$ & .697 \\
\hline Vitality & $31.65 \pm 52.1$ & $26.09 \pm 14.95$ & .143 \\
\hline Mental health & $29.64 \pm 11.29$ & $29.27 \pm 11.93$ & .857 \\
\hline Social function & $32.27 \pm 7.94$ & $32.67 \pm 9.18$ & .269 \\
\hline Pain & $21.41 \pm 4.93$ & $20.02 \pm 9.7$ & .325 \\
\hline General health & $49.86 \pm 5.25$ & $47.29 \pm 6.87$ & .086 \\
\hline
\end{tabular}


Table 4. Relationships between preoperative quality of life for patients with renal stones planned for treatment by percutaneous nephrolithotomy and preoperative GFR, double $\mathbf{J}$ stent, percutaneous nephrostomy and chronic diseases

\begin{tabular}{|c|c|c|c|c|c|c|c|c|c|c|c|c|}
\hline \multirow{4}{*}{$\begin{array}{l}\text { Preoperative } 8 \\
\text { domains of } \\
\text { quality of life }\end{array}$} & \multicolumn{12}{|l|}{ Factors } \\
\hline & \multicolumn{3}{|c|}{ Chronic diseases } & \multicolumn{3}{|c|}{ Estimated GFR value } & \multicolumn{3}{|c|}{ Preoperative double $\mathrm{J}$ stent } & \multicolumn{3}{|c|}{ Preoperative percutaneous nephrostomy } \\
\hline & Yes & No & $P$ & $\begin{array}{l}>60 \mathrm{ml} / \\
\mathrm{min} / 1.73 \mathrm{~m}^{2}\end{array}$ & $\begin{array}{l}<60 \mathrm{ml} / \\
\mathrm{min} / 1.73 \mathrm{~m}^{2}\end{array}$ & $P$ & Yes & No & $P$ & Yes & No & $P$ \\
\hline & $\overline{\mathbf{X}}+\mathbf{S D}$ & $\overline{\mathbf{X}}+\mathbf{S D}$ & & $\overline{\mathbf{X}}+\mathrm{SD}$ & $\overline{\mathbf{X}}+\mathrm{SD}$ & & $\overline{\mathbf{X}}+\mathrm{SD}$ & $\overline{\mathbf{X}}+\mathrm{SD}$ & & $\overline{\mathbf{X}}+\mathbf{S D}$ & $\overline{\mathbf{X}}+\mathrm{SD}$ & \\
\hline $\begin{array}{l}\text { Physical } \\
\text { function }\end{array}$ & $\begin{array}{l}30.78 \pm \\
7.4\end{array}$ & $\begin{array}{l}33.89 \pm \\
10.1\end{array}$ & .146 & $33.54 \pm 9.9$ & $30.13 \pm 9.8$ & .052 & $\begin{array}{l}24.25 \pm \\
5.1\end{array}$ & $\begin{array}{l}34.72 \pm \\
9.8\end{array}$ & $.001 * *$ & $32.53 \pm 13$ & $30.9 \pm 11$ & .810 \\
\hline $\begin{array}{l}\text { Physical role } \\
\text { limitation }\end{array}$ & $\begin{array}{l}28.95 \pm \\
8.75\end{array}$ & $\begin{array}{l}27.64 \pm \\
7.44\end{array}$ & .352 & $28.14 \pm 7.8$ & $27.03 \pm 6.9$ & .327 & $\begin{array}{l}26.86 \pm \\
3.6\end{array}$ & $\begin{array}{l}34.94 \pm \\
8.5\end{array}$ & $.011^{*}$ & $34.42 \pm 12$ & $29.71 \pm 9$ & .246 \\
\hline $\begin{array}{l}\text { Emotional role } \\
\text { limitation }\end{array}$ & $\begin{array}{l}37.55 \pm \\
8.49\end{array}$ & $\begin{array}{l}36.96 \pm \\
7.25\end{array}$ & .741 & $36.25 \pm 7.8$ & $35.2 \pm 5.47$ & .451 & $\begin{array}{l}30.1 \pm \\
4.00\end{array}$ & $\begin{array}{l}38.7 \pm \\
8.64\end{array}$ & $.034 *$ & $39.14 \pm 12$ & $35.73 \pm 8$ & .263 \\
\hline Vitality & $\begin{array}{l}33.96 \pm \\
6.7\end{array}$ & $\begin{array}{l}28.19 \pm \\
11.1\end{array}$ & .163 & $29.28 \pm 32$ & $24.5 \pm 10.4$ & .395 & $\begin{array}{l}18.98 \pm \\
6.5\end{array}$ & $\begin{array}{l}30.37 \pm \\
33\end{array}$ & $.001^{* *}$ & $29.77 \pm 27$ & $28.5 \pm 22$ & .902 \\
\hline Mental health & $\begin{array}{l}28.87 \pm \\
11.7\end{array}$ & $\begin{array}{l}30.75 \pm \\
12.7\end{array}$ & .482 & $29.95 \pm 12$ & $25.8 \pm 9.68$ & .136 & $\begin{array}{l}24.16 \pm \\
7.4\end{array}$ & $\begin{array}{l}33.58 \pm \\
13\end{array}$ & $.001 * *$ & $33.28 \pm 24$ & $29.5 \pm 19$ & .352 \\
\hline Social function & $\begin{array}{l}30.63 \pm \\
6.41\end{array}$ & $\begin{array}{l}32.42 \pm \\
9.06\end{array}$ & .369 & $32.42 \pm 8.8$ & $29.34 \pm 7.1$ & .253 & $\begin{array}{l}26.76 \pm \\
7.4\end{array}$ & $\begin{array}{l}33.59 \pm \\
8.8\end{array}$ & $.01^{*}$ & $32.14 \pm 9.8$ & $31.9 \pm 5$ & .741 \\
\hline Pain & $\begin{array}{l}26.53 \pm \\
10.2\end{array}$ & $\begin{array}{l}26.49 \pm \\
8.71\end{array}$ & .931 & $27.91 \pm 9.2$ & $25.4 \pm 7.26$ & .421 & $\begin{array}{l}25.28 \pm \\
5.4\end{array}$ & $\begin{array}{l}36.75 \pm \\
9.7\end{array}$ & $.001 * *$ & $30.96 \pm 10$ & $29.5 \pm 7$ & .825 \\
\hline General health & $\begin{array}{l}49.26 \pm \\
5.50\end{array}$ & $\begin{array}{l}50.07 \pm \\
8.71\end{array}$ & .402 & $48.87 \pm 5.5$ & $49.7 \pm 3.20$ & .363 & $\begin{array}{l}40.59 \pm \\
2.4\end{array}$ & $\begin{array}{l}49.94 \pm \\
8.2\end{array}$ & $.03 *$ & $50.88 \pm 13$ & $48.8 \pm 10$ & .314 \\
\hline
\end{tabular}

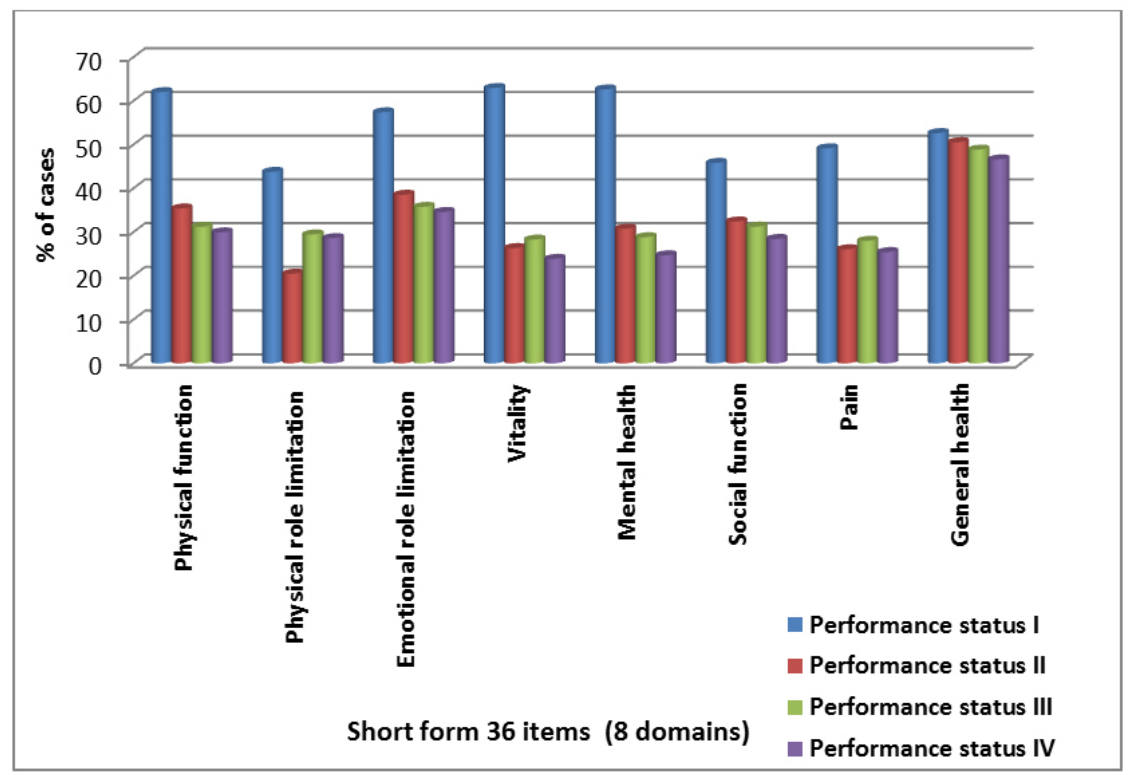

Figure 1. Relationship between preoperative performance status for patients with renal stones planned for treatment by percutaneous nephrolithotomy and preoperative quality of life

Tables 5 and 6 showed that there were statistical significant Table 7 showed that there were statistical significant differdifferences between the two groups of patients as regarding ences as regarding stone clearance three and six months after their postoperative complications using modified Clavien- surgery in study and control groups. There was none staDindo system $(P$-value $=.02)$. Grade II of postoperative tistical significant difference between postoperative hospital complications according to modified Clavien-Dindo system stays in all groups of patients was presented to be the most one.

Table 5. Postoperative complications for patients with renal stones treated by percutaneous nephrolithotomy

\begin{tabular}{|c|c|c|c|c|c|}
\hline \multirow{2}{*}{ Groups of patients } & \multicolumn{2}{|c|}{ Complications } & \multicolumn{2}{|c|}{ No complications } & \multirow{2}{*}{$\boldsymbol{P}$} \\
\hline & No. & $\%$ & No. & $\%$ & \\
\hline Study group $($ No. $=80)$ & 14 & 17.5 & 66 & 82.5 & \multirow{2}{*}{$.02 *$} \\
\hline Control group $($ No. $=80)$ & 25 & 31.25 & 55 & 68.75 & \\
\hline
\end{tabular}


Table 8 revealed that all patients in study and control groups .0001) between patients' knowledge in study and control had unsatisfactory level of knowledge at the time of assess- groups in relation to total knowledge score.

ment. There highly statistical significant difference $(P<$

Table 6. Frequency distribution of postoperative complications according to modified Clavien-Dindo grading system in patients with renal stones treated by percutaneous nephrolithotomy

\begin{tabular}{|c|c|c|c|c|}
\hline \multirow{2}{*}{$\begin{array}{l}\text { Complications and its grades } \\
\text { (More than one) }\end{array}$} & \multicolumn{2}{|c|}{ Study group $($ No. $=\mathbf{8 0})$} & \multicolumn{2}{|c|}{ Control group $(\mathrm{No} .=80)$} \\
\hline & No. & $\%$ & No. & $\%$ \\
\hline \multicolumn{5}{|l|}{ Grade I complications } \\
\hline Hematuria & 1 & 1.25 & 3 & 3.75 \\
\hline Fever & 2 & 2.5 & 3 & 3.75 \\
\hline Wound infection & - & - & 1 & 1.25 \\
\hline Urine leakage & 4 & 5 & 1 & 1.25 \\
\hline Repeated vomiting & 2 & 2.5 & 1 & 1.25 \\
\hline Chest pain and cough & 1 & 1.25 & 1 & 1.25 \\
\hline \multicolumn{5}{|l|}{ Grade II complications } \\
\hline Hematuria (Administer blood transfusion) & 2 & 2.5 & 8 & 10 \\
\hline Urinary tract infection & - & - & 1 & 1.25 \\
\hline Repeated vomiting & 1 & 1.25 & 4 & 5 \\
\hline \multicolumn{5}{|l|}{ Grade III complications } \\
\hline Hematuria (Perform renal angioemobilization) & - & & 1 & 1.25 \\
\hline Obstruction and renal colic due to blood clots(Insert double J ) & 2 & 2.5 & 1 & 1.25 \\
\hline
\end{tabular}

Table 7. Stone clearance immediately postoperative, 3 months and 6 months after surgery and length of hospital stays in patients with renal stones treated by percutaneous nephrolithotomy

\begin{tabular}{|c|c|c|c|c|c|}
\hline \multirow{2}{*}{ Items } & \multicolumn{2}{|c|}{ Study group $($ No. $=80)$} & \multicolumn{2}{|c|}{ Control group $($ No. $=80)$} & \multirow{2}{*}{$\boldsymbol{P}$} \\
\hline & No. & $\%$ & No. & $\%$ & \\
\hline \multicolumn{6}{|l|}{ Stone free } \\
\hline Immediately postoperative & 47 & 58.75 & 49 & 61.25 & .274 \\
\hline Three months after surgery & 68 & 85 & 56 & 70 & $.04 *$ \\
\hline Six months after surgery & 76 & 95 & 62 & 77.5 & $.03 *$ \\
\hline Postoperative length of hospital stays & \multicolumn{2}{|c|}{$3.76 \pm 1.32$} & \multicolumn{2}{|c|}{$4.18 \pm 1.0$} & .417 \\
\hline
\end{tabular}

$* P \leq .05$

Table 8. Comparison between assessment and follow up total score of patients' knowledge (study and control groups)

\begin{tabular}{|c|c|c|c|c|c|c|c|}
\hline \multirow{2}{*}{ Patients' knowledge } & \multicolumn{3}{|c|}{ Study group $($ No. $=80)$} & \multicolumn{3}{|c|}{ Control group $($ No. $=80)$} & \multirow{2}{*}{$\boldsymbol{P}$} \\
\hline & No. & $\%$ & $\overline{\mathbf{X}} \pm \mathrm{SD}$ & No. & $\%$ & $\overline{\mathbf{X}} \pm \mathrm{SD}$ & \\
\hline \multicolumn{8}{|l|}{ At assessment } \\
\hline Satisfactory & - & - & $10.62 \pm 3.86$ & - & - & $11.14 \pm 5.32$ & .253 \\
\hline Unsatisfactory & 80 & 100 & & 80 & 100 & & \\
\hline \multicolumn{8}{|l|}{ Before discharge } \\
\hline Satisfactory & 80 & 100 & $46.37 \pm 4.65$ & - & - & $19.21 \pm 5.25$ & $<.0001 * * *$ \\
\hline Unsatisfactory & - & - & & 80 & 100 & & \\
\hline \multicolumn{8}{|l|}{ After 3 months } \\
\hline Satisfactory & 77 & 96.25 & $43.71 \pm 4.83$ & - & - & $16.82 \pm 3.69$ & $<.0001 * * *$ \\
\hline Unsatisfactory & 3 & 3.75 & & 80 & 100 & & \\
\hline \multicolumn{8}{|l|}{ After 6 months } \\
\hline Satisfactory & 76 & 95 & $42.38 \pm 5.76$ & - & - & $14.21 \pm 2.58$ & $<.0001 * * *$ \\
\hline Unsatisfactory & 4 & 5 & & 80 & 100 & & \\
\hline
\end{tabular}

Note. Total knowledge score is $20 .{ }^{* *} P \leq .0001$. 
Figure 2 illustrated that there were highly statistical significant differences between postoperative quality of life and physical function, physical role limitation, vitality, mental health, pain and general health in study and control groups of patients. There were non statistical significant differences between postoperative quality of life and emotional role limitation and social function in study and control groups of

\section{patients.}

Figures 3 and 4 illustrated that there were high significant relations between all domains of postoperative quality of life and stone free. There were significant relations between all domains of postoperative quality of life and postoperative performance status.

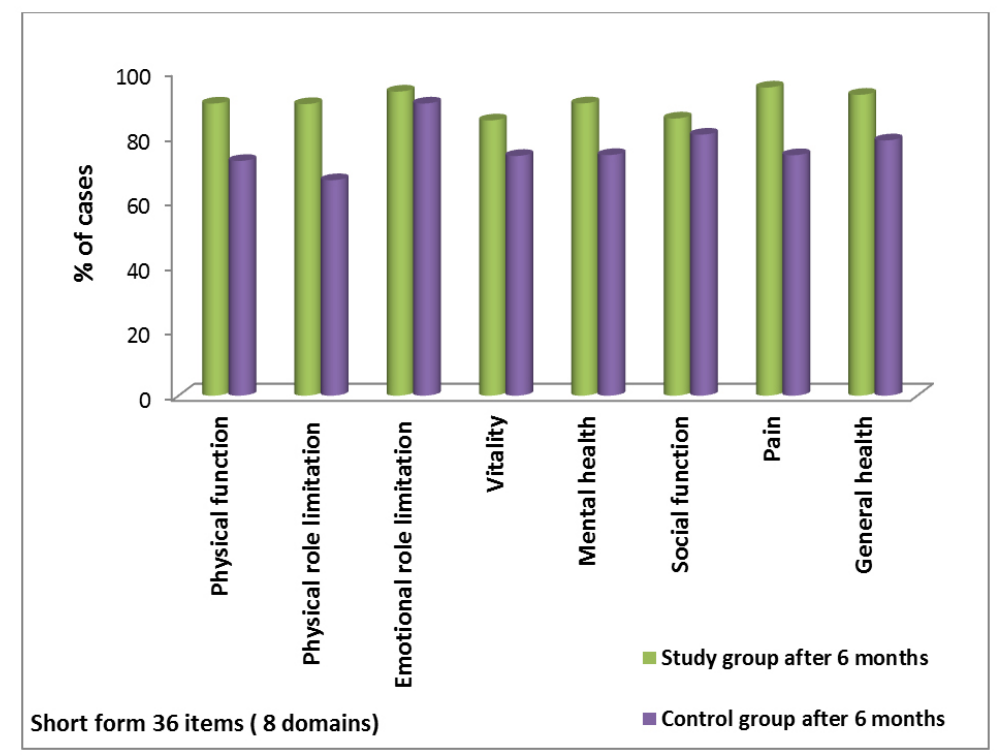

Figure 2. Postoperative quality of life using 8 domains of the short form 36 items questionnaire in study and control groups of patients with renal stones treated by percutaneous nephrolithotomy

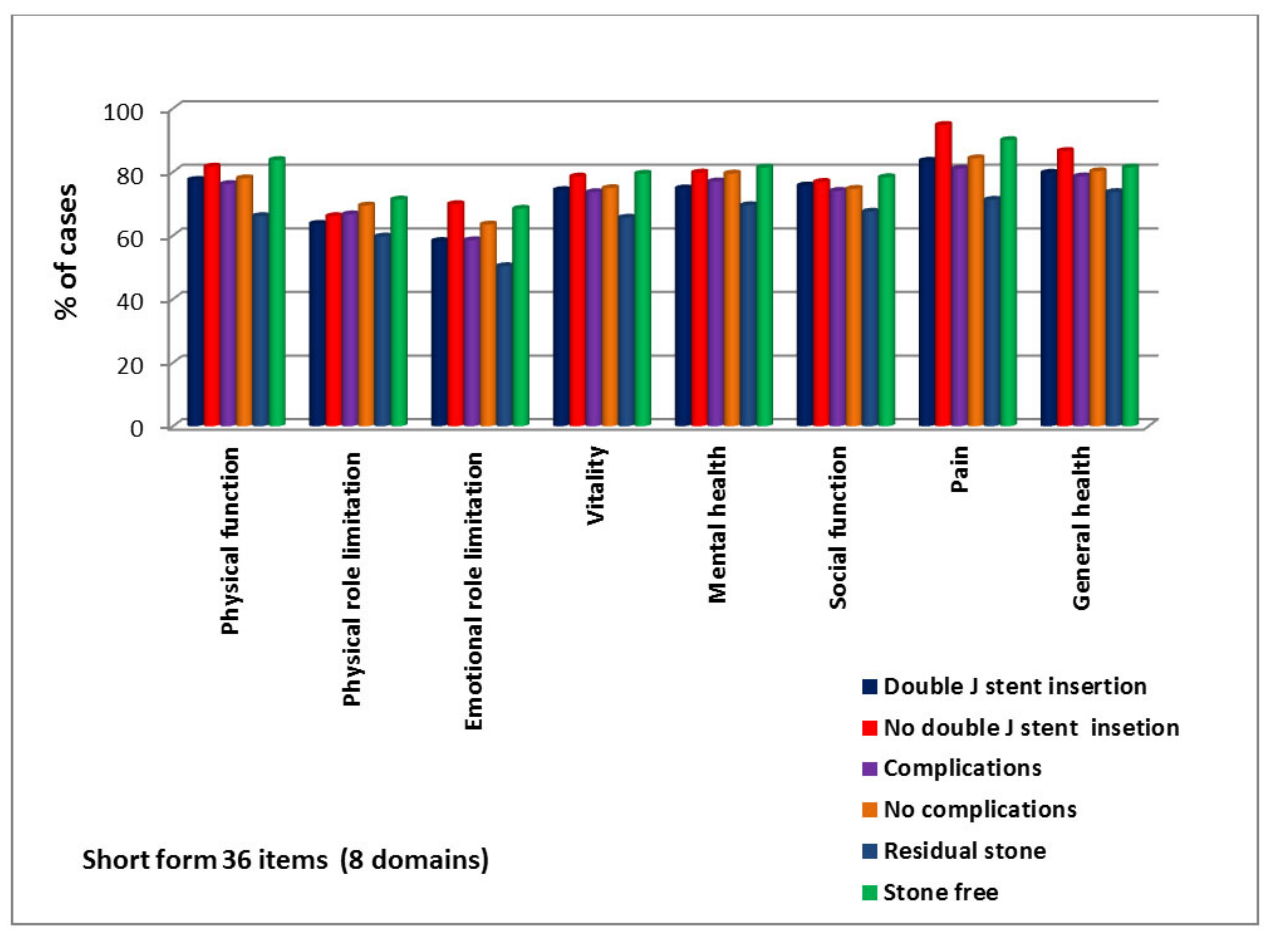

Figure 3. Relationships between postoperative quality of life and postoperative double $\mathrm{J}$ stent, complications and stone free in patients with renal stones treated by percutaneous nephrolithotomy 


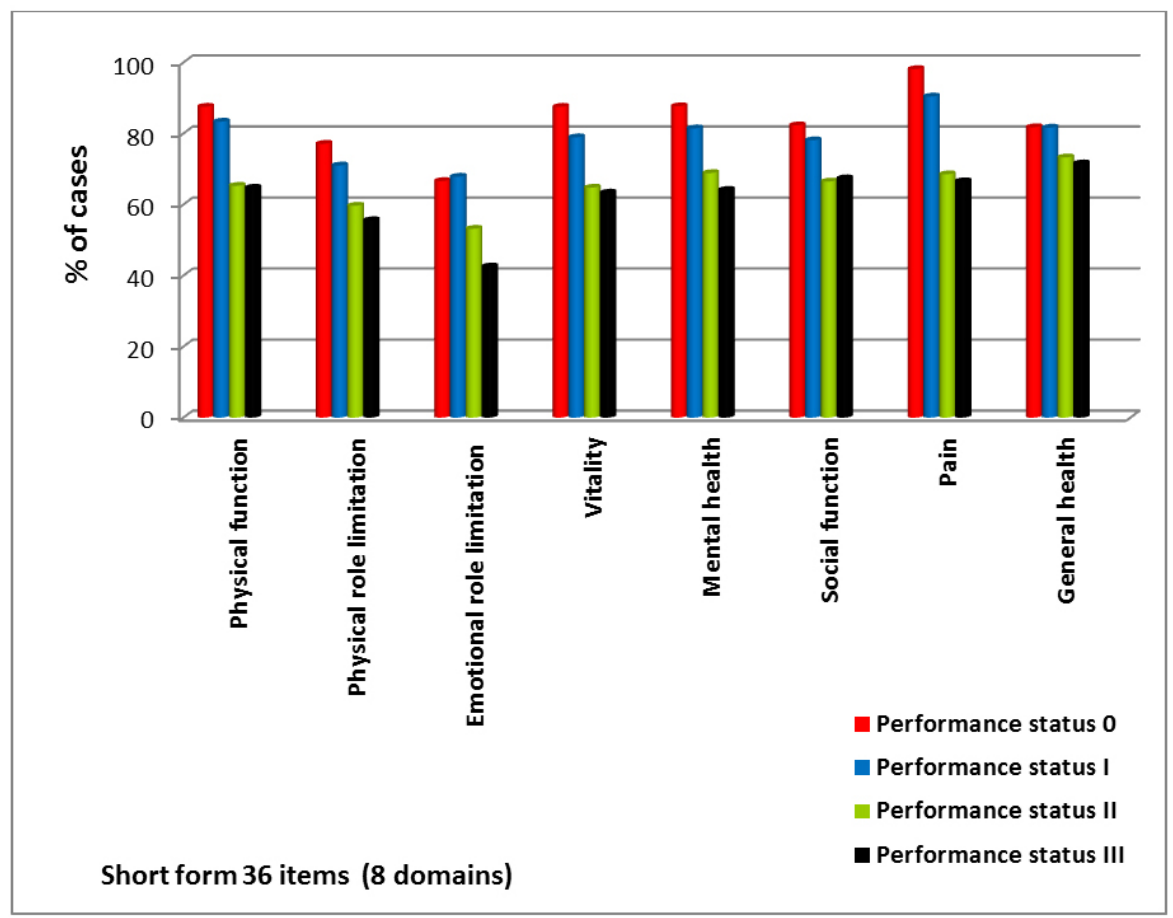

Figure 4. Relationship between postoperative quality of life and postoperative performance status in patients with renal stones treated by percutaneous nephrolithotomy

Figure 5 illustrated that there was highly statistical significant postoperative health change after 6 months. difference between study and control groups as regarding

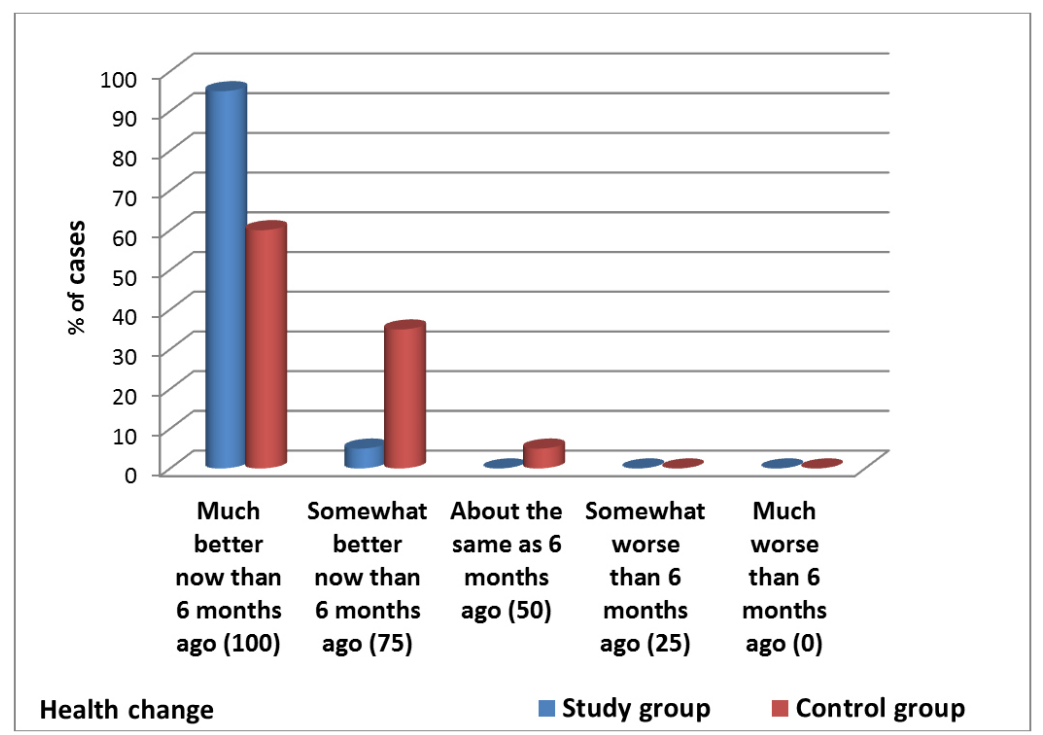

Figure 5. Comparison between health changes of study and control groups of patients after 6 months

\section{Discussion}

The importance of assessment of quality of life for patients with renal stones is driven from its high incidence, severe symptoms, high prevalence and recurrence rate. ${ }^{[2]}$

The present study showed that more than half of patients in both groups were males with a mean age of $38.52 \pm 15.84$ years for study and $40.32 \pm 12.87$ years for control groups and majority of them were educated and employed.

In the same line this similar to study stated that renal stone more common in males with a mean age of 41 years. ${ }^{[14]}$ 
Presence of double $\mathbf{J}$ stent in preoperative periods was the most significant factor affecting the eight domains of quality of life. This can be explained by the side effects of double $\mathrm{J}$ stent including pain due to bladder irritation, increase frequency, pain during micturation, vesicoureteral reflux and urinary tract infection. Other studies reported similar results that pain associated with double $\mathrm{J}$ stent interferes with daily activities, mental well-being and reduce quality of life. ${ }^{[15]}$

Performance status was found to affect the physical role limitation and the social function domains. This is because deterioration of performance status affects the ability of the patient to perform the usual daily activities. In our study, the presence of chronic disease was found to have no impact on quality of life for patients with renal stone. Similar result was reported by Arafa and Rabah, 2010. ${ }^{[2]}$

The stone free should not be evaluated until every chance of spontaneous passage of residual fragment is exhausted and after certain period of time of followed instructions presentd in the teaching booklet by study group patients which educated about them by the main researcher mainly after 3 months. The total stone free rate of control group improved but still lower than study group. Lower stone free rate was statistically significant between study and control groups after three and six months. This can be explained by the effect of patients education on study group.

In the same line, study reported similar increase of stone-free rates after discharge and at the end of follow-up in percutaneous nephrolithotomy. ${ }^{[16,17]}$

Significant difference was found between the total complications rate in both groups. Grade II complications were significantly higher in control group than study group. This can be explained by the effect of nursing interventions and patients education on study group.

Previous studies on complications of surgical interventions for renal stones showed high variability. ${ }^{[18]}$ This variability is most probably due to the lack of a uniform system for the definition and the assessment of these complications and due to the different ways of display. Some report only urinary complications some include extra-urinary complications and others divide complications into minor and major ones. In addition, there is no consensus about which complications are major and which are minor. ${ }^{[19]}$

As expected, the treatment of renal stone improves all domains of quality of life. This declares the importance of efficient management of renal stone disease for achieving better quality of life. This was also emphasized by the finding of the highly significant effect of stone free on postoperative quality of life in addition to the effect of nursing interven- tions and patients education (teaching booklet). The main aim of any modality for management of renal stones is to remove all stones. Being free of stones means relief of patients' symptoms which means a better quality of life. But the patients' perception of treatment effect are complex and do not reflect the outcomes of tradition interest as stone free rates and complication rate. In our study all domains of quality of life improve in study group patients.

These agree with the study of Perez-Fentes et al. (2015) who stated that there is overall improvement on quality of life for patients after percutaneous nephrolithotomy. ${ }^{[20]}$ Other study reported that quality of life improved in only half of patients who had been rendered stone free. ${ }^{[21-23]}$

In our study quality of life for study group patients was found to be significantly higher than control group regarding domains of the short form 36 items questionnaire except emotional role limitation and social functioning. This can be explained by higher stone free rate and the effect of nursing interventions and patients education including home care and discharge instructions (teaching booklet).

Our study disagrees with Arafa and Rabah (2010) who reported that patients treated by percutaneous nephrolithotomy had significantly low scores for all domains except body pain. $^{[2]}$

On contrary to preoperative results, the presence of double $\mathbf{J}$ stent in postoperative period was found to be not related to quality of life. This difference between effect of double $\mathbf{J}$ stent on quality of life in the preoperative and postoperative periods can be explained by the short term use of double $\mathbf{J}$ stent postoperatively especially in patients who achieved a free of stone state.

In our study, all patients in study and control groups at the time of assessment had unsatisfactory level of knowledge regarding percutaneous nephrolithotomy. This can be explained by the fact that patients didn't receive enough information from health care team regarding their conditions. Lack of knowledge about medications, diet, wound care, rest and activity can lead to many different complications and affect on quality of life.

At the time of follow up (before discharge, after 3 and 6 months) the level of patients' knowledge in study group was improved significantly and led to high stone free rate, lower complications and highly significant improvement on quality of life .

Regarding health comparison question (health change), this question was asked to patients at the end of follow up periods (after 6 months) to compare health change between the two 
groups. Majority of patients $(100 \%)$ in study group were having health improvement $(95 \%$ much better improvement and 5\% somewhat better improvement), while in control group (60\% much better improvement, $35 \%$ somewhat better improvement and $5 \%$ about the same). This could be due to the effect of nursing interventions and patients education (teaching booklet) for study group patients.

The results were supported by Piper and Stewart (2009) ${ }^{[24]}$ who stated that effective education will result in changes that illustrate increased information about special medical and health related issues for long period of time. Effective health education will yield short and long term changes in behaviors that reduce risky behaviors and reduce the incidence of many postoperative complications. Changes in behaviors can be documented through evaluator observation and learner feedback, or through more formal means.

This study findings were supported by the study of Maloney and Weiss, 2008 ${ }^{[25]}$ entitled as "Patients' perceptions of hospital discharge informational content" which reported that information needs may be different according to patients' characteristics. Discharge teaching is a critical component of discharge sheet to facilitate transition from hospital to home and to reduced rate of post discharge complications and readmission and improve health.

\section{CONCLUSION AND RECOMMENDATIONS}

\subsection{Conclusion}

Presence of double $\mathbf{J}$ stent and performance status are the main factors affecting preoperative quality of life for pa- tients with renal stones which affect all domains of quality of life except general health in double $\mathbf{J}$ stent and vitality and general health in performance status. Before patients education (teaching booklet) all patients in both groups had unsatisfactory level of knowledge. There was a high significant improvement on patients' knowledge (at the time of follow up) for study group patients after introduce the teaching booklet. Quality of life for both groups were improved after treatment of renal stones however, study group patients have better quality of life than control group patients due to the effect of nursing interventions and patients education (teaching booklet). The total stone free rate after three and six months in both groups were improved but still higher in study group than control group due to the effect of patints ducation on study group. Providing nursing interventions and improving patients' level of knowledge had a significant effect on reducing or preventing postoperative complications and improving quality of life. So, patients after percutaneous nephrolithotomy are in essential need for special nursing interventions and education to help them to avoid many postoperative complications and thus improve their health.

\subsection{Recommendations}

Stone clearance after percutaneous nephrolithotomy should be assessed 3 months after the procedure. Patients with percutaneous nephrolithotomy should receive careful nursing interventions and education (especially for home care and discharge instructions) to improve quality of life.

\section{CONFliCtS OF INTEREST Disclosure}

The authors declare that there is no conflict of interest.

\section{REFERENCES}

[1] Rafiei H, Malekpoor F, Amiri M, et al. Kidney stone development among older adults in Iran. Journal of the Indian Academy of Geriatrics. 2014; 10: 10-13.

[2] Arafa MA, Rabah DM. Study of quality of life and its determinants in patients after urinary stone fragmentation. Health and Quality of Life Outcomes. 2010; 8(1): 1. PMid:20959005 https: //doi.org/10.1186/1477-7525-8-119

[3] Wang Z, Xu L, Su Z, et al. Invasive management of proximal ureteral calculi during pregnancy. Urology. 2014; 83(4): 745-749. PMid:24508478 https://doi.org/10.1016/j .urology . 2013 .11 .031

[4] Knoll T, Buchholz N, Wendt-Nordahl G. Extracorporeal shockwave lithotripsy vs. percutaneous nephrolithotomy vs. flexible ureterorenoscopy for lower-pole stones'. Arab Journal of Urology. 2012; 10(3): 336-341. PMid:26558046 https://doi.org/10.1 016/j.aju.2012.06.004

[5] Weis J, Arraras JI, Conroy T, et al. Development of an EORTC quality of life phase III module measuring cancer related fatigue
(EORTC QLQ.FA13). Psycho Oncology. 2013; 22(5): 1002-1007. PMid:22565359 https://doi.org/10.1002/pon. 3092

[6] Bozkurt OF, Resorlu B, Yildiz Y, et al. Retrograde intrarenal surgery versus percutaneous nephrolithotomy in the management of lowerpole renal stones with a diameter of 15 to $20 \mathrm{~mm}$. Journal of Endourology. 2011; 25(7): 1131-1135. PMid:21657824 https: //doi.org/10.1089/end.2010.0737

[7] Antonelli JA, Pearle MS. Advances in percutaneous nephrolithotomy, Urologic Clinics of North America. 2013; 40(1): 99113. PMid:23177638 https://doi.org/10.1016/j .ucl. 2012 .09 .012

[8] Liu YW, et al. About B-guided percutaneous nephrolithotomy holmium laser lithotripsy in perioperative nursing. Journal of Clinical Medicine. 2011; 1: 31 .

[9] Haddad S, Spir A, Craft S, et al. Benefits of patient education. Patient Education Institute. 2013.

[10] Levey AS, Coresh J, Greene T, et al. Expressing the Modification of Diet in Renal Disease Study equation for estimating glomerular filtration rate with standardized serum creatinine values. Clin- 
ical chemistry. 2007; 53(4): 766-772. PMid:17332152 https: //doi.org/10.1373/clinchem.2006.077180

[11] Oken MM, Creech RH, Tormey DC, et al. Toxicity and response criteria of the Eastern Cooperative Oncology Group. American Journal of Clinical Oncology. 1982; 5(6): 649-656. PMid:7165009 https://doi.org/10.1097/00000421-198212000-00014

[12] Dindo D, Demartines N, Clavien PA. Classification of surgical complications: a new proposal with evaluation in a cohort of 6336 patients and results of a survey. Annals of Surgery. 2004; 240(2): 205-213. PMid:15273542 https://doi.org/10.1097/01.sla.0000133 083.54934.ae

[13] Ware Jr JE, Sherbourne CD. The MOS 36-item short-form health survey (SF-36): I. Conceptual framework and item selection. Medical Care. 1992. PMid:1593914 https://doi.org/10.1097/000056 50-199206000-00002

[14] Bayar G, Tanriverdi O, Taskiran M, et al. Comparison of laparoscopic and open ureterolithotomy in impacted and very large ureteral stones. Urology Journal. 2014; 11(2): 1423. PMid:24807754

[15] Penniston K, Nakada S. Treatment expectations and health-related quality of life in stone formers. Current Opinion in Urology. 2016; 26(1): 50-55. PMid:26626885 https://doi .org/10 1097/MOU. 0000000000000236

[16] Matlaga BR, Meckley LM, Kim M, et al. Management patterns of medicare patients undergoing treatment for upper urinary tract calculi. Journal of Endourology. 2014; 28(6): 723-728. PMid:24344933 https://doi.org/10.1089/end.2013.0580

[17] Aydemir H, Budak S, Kumsar Ş, et al. Efficacy of surgical techniques and factors affecting residual stone rate in the treatment of kidney stones. Turkish Journal of Urology. 2014; 40(3): 144.
[18] Aminsharifi A, Irani D, Masoumi M, et al. The management of large staghorn renal stones by percutaneous versus laparoscopic versus open nephrolithotomy: a comparative analysis of clinical efficacy and functional outcome. Urolithiasis. 2016. https ://doi . org/10 $.1007 / \mathrm{s} 00240-016-0877-6$

[19] El-Husseiny T, Buchholz N. The role of open stone surgery. Arab Journal of Urology. 2012; 10(3): 284-288. PMid:26558038 https : //doi.org/10.1016/j.aju.2012.03.004

[20] Perez-Fentes DA, Gude F, Blanco B, et al. Percutaneous nephrolithotomy: Short-and long-term effects on quality of life. Journal of Endourology. 2015; 29(1): 13-17. PMid:24708396 https://doi . org/10.1089/end.2014.0081

[21] Penniston KL, Nakada SY. Development of an instrument to assess the health related quality of life of kidney stone formers. The Journal of Urology. 2013; 189(3): 921-930.

[22] Chandrasekar T, Monga M, Nguyen M, et al. Internet-Based Patient Survey on Urolithiasis Treatment and Patient Satisfaction. Journal of Endourology. 2015; 29(6): 725-729. PMid:25365030 https://doi.org/10.1089/end.2014.0643

[23] Turney B, Reynard J. Obtaining patient feedback in an outpatient lithotripsy service is facilitated by use of a touch-screen tablet survey. Urolithiasis. 2014; 42(4): 317-321. PMid:24747981 https: //doi.org/10.1007/s00240-014-0662-3

[24] Piper S, Stewart P. Health Promotion for Nurses: Theory and practice, United Kingdom: Taylor and Francis. 2009.

[25] Maloney RL, Weiss M. Clinical Nursing Research, Patients' Perceptions of Hospital Discharge. Marquette University, SAGE Publications; 2008; 17(3): 200-219. 